University of Wollongong

Research Online

Faculty of Engineering and Information

Faculty of Engineering and Information

Sciences - Papers: Part A

Sciences

$1-1-2012$

Investigation of the effects of pipe wall roughness and pipe diameter on the decompression wave speed in natural gas pipelines

Cheng Lu

University of Wollongong, chenglu@uow.edu.au

Guillaume Michal

University of Wollongong, gmichal@uow.edu.au

Alhoush Elshahomi

University of Wollongong, aes738@uowmail.edu.au

Ajit R. Godbole

University of Wollongong, agodbole@uow.edu.au

Phillip Venton

Venton and Associates

See next page for additional authors

Follow this and additional works at: https://ro.uow.edu.au/eispapers

Part of the Engineering Commons, and the Science and Technology Studies Commons

Research Online is the open access institutional repository for the University of Wollongong. For further information contact the UOW Library: research-pubs@uow.edu.au 


\title{
Investigation of the effects of pipe wall roughness and pipe diameter on the decompression wave speed in natural gas pipelines
}

\author{
Abstract \\ The shock tube experimental results have shown clearly that the decompression wave was slowed down \\ in a pipe with a rough inner surface relative to that in a smooth pipe under comparable conditions. In the \\ present paper a one-dimensional dynamic simulation model, named EPDECOM, was developed to \\ investigate the effects of pipe wall roughness and pipe diameter on the decompression wave speed. \\ Comparison with experimental results showed that the inclusion of frictional effects led to a better \\ prediction than that of the widely used model implemented in GASDECOM. EPDECOM simulation results \\ showed that the effect of roughness on the decompression wave speed is significant for pipe diameters \\ less than $250 \mathrm{~mm}$. However the decompression wave speed is nearly independent of the roughness for \\ diameters above $250 \mathrm{~mm}$ as the frictional effect becomes negligible at such diameters.

\section{Disciplines} \\ Engineering | Science and Technology Studies

\section{Publication Details} \\ Lu, C., Michal, G., Elshahomi, A., Godbole, A., Venton, P., Botros, K. K., Fletcher, L. \& Rothwell, B. (2012). \\ Investigation of the effects of pipe wall roughness and pipe diameter on the decompression wave speed \\ in natural gas pipelines. 9th International Pipeline Conference, Volume 3: Materials and Joining (pp. \\ 315-322). United States: ASME.
}

\section{Authors}

Cheng Lu, Guillaume Michal, Alhoush Elshahomi, Ajit R. Godbole, Phillip Venton, K K. Botros, Leigh Fletcher, and B Rothwell 


\title{
INVESTIGATION OF THE EFFECTS OF PIPE WALL ROUGHNESS AND PIPE DIAMETER ON THE DECOMPRESSION WAVE SPEED IN NATURAL GAS PIPELINES
}

\author{
C. Lu, G. Michal, A. Elshahomi, A. Godbole \\ University of Wollongong \\ Wollongong, NSW, Australia
}

\author{
P. Venton \\ Venton \& Associates Pty Ltd \\ Bundanoon, NSW, Australia \\ B. Rothwell \\ Brian Rothwell Consulting Inc. \\ Calgary, AB, Canada
}

K. Botros

NOVA Research and

Technology Centre

Calgary, AL, Canada

\author{
L. Fletcher \\ Welding and Pipeline Integrity \\ Bright, Victoria, Australia
}

\begin{abstract}
The shock tube experimental results have shown clearly that the decompression wave is slowed down in a shock tube with a rough inner surface relative to that in a smooth tube under the same (or very similar) conditions. In the present paper a one-dimensional dynamic simulation model, named EPDECOM, was developed to investigate the effects of pipe wall roughness and pipe diameter on the decompression wave speed. Comparison with experimental results has shown that EPDECOM performs better than the commonly used model GASDECOM. EPDECOM simulation results show that the effect of roughness on the decompression wave speed is significant for small diameter pipes $(D<\sim 250 \mathrm{~mm})$, while this effect is negligible for pipes with $D \geq \sim 250 \mathrm{~mm}$. It is also found that the decompression wave speed is nearly independent on pipe diameter for $D \geq 250 \mathrm{~mm}$ pipes.
\end{abstract}

\section{INTRODUCTION}

Fracture propagation is a significant issue for pipelines transporting gases and the need to arrest a running fracture in a pipeline is paramount to the integrity and safety of the pipeline's operation. The Battelle Two-Curve Model (BTCM) is the most commonly used approach for the prediction of the minimum linepipe toughness ("arrest toughness") required to arrest a running fracture [1]. The BTCM involves the superposition of two curves: the gas decompression wave speed characteristic and the fracture propagation speed characteristic, each as a function of local gas pressure. The boundary between arrest and propagation of a running fracture is represented by tangency between the decompression curve and the fracture curve, the arrest toughness is the value corresponding to this condition.

A number of full-scale burst tests were conducted to investigate pipeline gas decompression since the 1970s [2-8]. However, full scale burst tests are prohibitively costly, except for major projects. Botros et al. have experimentally investigated the decompression wave speed using a small diameter NPS 2 shock tube [9, 10]. Phillips and Robinson have reported decompression wave speed measurements using an NPS 6 shock tube [11]. In both full scale bust tests and shock tube tests, the decompression wave speed can be determined from pressure-time traces measured by transducers mounted at different locations along the pipe. For any pressure level below the initial pressure, the time of arrival of the decompression wave at each successive pressure transducer can be determined, and the corresponding propagation speed $W$ can be calculated using a linear fit of distance from initiation against arrival time. Such calculations are repeated for progressively lower pressures, and the results presented in terms of the decompression wave speed $W$ as a function of pressure $P$.

Many models were developed to predict the decompression wave speed [12]. GASDECOM is the most widely used model. In GASDECOM, the decompression wave speed $(W)$ can be calculated by

$$
W=C-u
$$

where $C$ is the speed of sound behind the decompression wave and $u$ is the mean outflow speed behind the decompression wave. 
Increments in pressure and density are used to calculate $C$ and $u$. The outflow speed $u$ at any given pressure is the sum of incremental $\Delta u$ determined from

$$
u=\sum_{\rho}(\Delta u)_{s}
$$

where

$$
(\Delta u)_{s}=C \frac{(\Delta \rho)_{s}}{\rho}
$$

and $\rho$ is the mass density, the subscript $s$ indicates a value on the isentrope. The BWRS (Benedict-Webb-Rubin-Starling) Equation of State (EOS) is used to calculate thermodynamic properties of the gas (speed of sound and density) in GASDECOM.

Several models have followed the approach of GASDECOM. A detailed review was given in Ref. [11]. The Advantica model uses the cubic LRS (London Research Station) EOS [13], which is similar to the RKS (RedlichKwong-Soave) EOS. The PR (Peng-Robinson) equation is found to accurately predict the initial speed of sound, so the results in Advantica model are adjusted (multiplied by a constant factor) to match this value at the initial conditions. The decompression model developed by Groves et al. adopts the RKS EOS to determine the thermodynamic properties [14]. The PipeDecom model allows the effects of non-equilibrium thermodynamics to be represented in the calculation. Delayed liquid droplet formation can be included in the wave velocity prediction through manually changing nucleation temperature [11]. Jones and Gough have developed a computer program DECAY [15], which follows the GASDECOM approach in modeling single phase decompression in a pipe undergoing fracture propagation. For two-phase condition, the mass, momentum and energy conservation equations are used to calculate the velocity. All properties are calculated using the Peng-Robinson EOS in DECAY. The approach taken in the model developed by Makino et al. [16] is similar to the model of Jones and Gough, but it uses the BWRS EOS.

Current methods used to predict the decompression wave speed are inadequate, as shown below:

- Recent shock-tube tests conducted by Botros et al [9] have shown that the decompression wave speed decreases as the non-dimensional wall roughness $(\varepsilon / D)$ is increased. GASDECOM-type models cannot include the effects of wall roughness and pipe diameter on the decompression wave speed.

- Botros [17] compared the densities in the dense phase region as predicted by five EOSs: GERG, AGA-8, BWRS, PR and RKS, with measured values for different hydrocarbon mixtures. It was found that the GERG EOS outperforms all other equations in the region up to $P=$ $30 \mathrm{MPa}$ and $T>-8^{\circ} \mathrm{C}$. However, GERG has not been implemented in the commonly used decompression wave speed models
The present study aims to develop a new decompression wave speed model with incorporation of GERG-2008 EOS to take into account the effects of wall roughness and pipe diameter.

\section{SHOCK TUBE EXPERIMENT}

Shock tube tests were carried out at the TransCanada Pipeline Gas Dynamics Test Facility in Didsbury, Alberta, Canada [9]. The tests were designed to understand and quantify the effects of pipe diameter and wall friction on the decompression wave speed.

The shock tube consists of four spool pieces of NPS 2 stainless steel pipe making up a total length of 42 meters. They are made of NPS 2 x $11.1 \mathrm{~mm}$ WT, SCH XX, ASTM A312, $316 \mathrm{SS}$ seamless tube (I.D. $=38.1 \mathrm{~mm})$. All individual spools were designed for $41.370 \mathrm{MPa}$ pressure with a design factor of 0.8 and a location factor of 0.625 . All spool pieces were internally honed to a roughness $R Z$ less than $0.635 \mu \mathrm{m}$, except for the rough tube tests, for which only Spool \#1 was replaced with one having internal surface roughness $\mathrm{RZ}=3.81$ $\mu \mathrm{m}$. A total of 16 Endevco dynamic pressure transducers were mounted along the length of the shock tube, 13 of which were mounted on the front spool where the rupture disc was located.

Table 1 Shock tube test conditions

\begin{tabular}{|c|c|c|}
\hline & $\begin{array}{c}\text { Reference Test } \\
\text { (Lean gas) }\end{array}$ & $\begin{array}{c}\text { Test 4 } \\
\text { (Rich gas) }\end{array}$ \\
\hline $\mathrm{P}_{\mathrm{i}}(\mathrm{MPa})$ & 18.438 & 19.837 \\
\hline $\mathrm{T}_{\mathrm{i}}\left({ }^{\circ} \mathrm{C}\right)$ & 17 & 11.37 \\
\hline $\mathrm{C} 1$ & 97.2754 & 82.3030 \\
\hline $\mathrm{C} 2$ & 1.43651 & 6.86748 \\
\hline $\mathrm{C} 3$ & 0.26693 & 7.13351 \\
\hline $\mathrm{iC} 4$ & 0.03208 & 0.75241 \\
\hline $\mathrm{nC} 4$ & 0.04322 & 0.98587 \\
\hline $\mathrm{iC} 5$ & 0.01015 & 0.00668 \\
\hline $\mathrm{nC5}$ & 0.00749 & 0.00475 \\
\hline $\mathrm{C} 6+$ & 0.00919 & 0.0064 \\
\hline $\mathrm{N} 2$ & 0.55554 & 0.47430 \\
\hline $\mathrm{CO} 2$ & 0.363498 & 1.465631 \\
\hline
\end{tabular}

The test program consisted of a total of 8 tests conducted with various gas compositions representative of conventional natural gas mixture (Reference Test) and three other medium rich, rich and ultra rich mixtures. These 8 rupture tests were conducted using the smooth shock tube, and then repeated using the rough tube for the same nominal gas compositions and initial pressures and temperatures. The detailed experimental conditions and results have been given in Ref. [9]. The shock tube experimental results have shown clearly that the decompression wave is slowed down in a shock tube with a rough inner surface relative to that in a smooth tube under the same (or very similar) conditions. Table 1 lists two typical tests (Reference Test for lean gas and Test 4 for rich gas) using rough tube. 


\section{DECOMPRESSION WAVE SPEED MODEL}

A new decompression wave speed model, named EPDECOM, has been developed in the present study. This model solves the following one-dimensional dynamic differential equation (Eqn. (4)) using the finite difference method. Eqn. (4) is derived assuming that the outflow speed and pressure are constant along the pipe radial direction:

$$
\frac{\partial P}{\partial t}+(C-u) \frac{\partial P}{\partial x}-\frac{\rho C f}{2 D} u^{2}=0
$$

here $P$ is the pressure, $C$ the speed of sound, $u$ the outflow speed, $t$ the time, $x$ the distance from the rupture, $\rho$ the density, $f$ the Darcy friction factor or Moody friction factor and $D$ the pipe diameter. The friction factor is currently calculated by Eqns. (5) and (6).

$$
\begin{aligned}
& f=\left(\frac{1}{-1.8 \log _{10}(A)}\right)^{2} \\
& A=\frac{6.9}{\operatorname{Re}}+\left(\frac{\varepsilon / D}{3.7}\right)^{1.11}
\end{aligned}
$$

where $R e$ is the Reynolds number and $\varepsilon$ is the pipe wall roughness.

The isentropic condition is assumed in EPDECOM. Other auxiliary equations used with Eqn. (4) include:

$$
\begin{gathered}
\partial u=C \frac{\partial \rho}{\rho} \\
C=\sqrt{\frac{\partial P}{\partial \rho}} \\
\rho=f_{1}(P, s) \\
T=f_{2}(P, s)
\end{gathered}
$$

where $T$ is the temperature and $s$ is the entropy. $f_{1}$ and $f_{2}$ are functions of $P$ and $s$, which are given by the GERG-2008 EOS.

GERG-2008 EOS [18] covers the gas phase, the liquid phase, the supercritical region, and vapour-liquid equilibrium states for natural gases and other mixtures consisting of the 21 components methane, nitrogen, carbon dioxide, ethane, propane, n-butane, isobutane, n-pentane, isopentane, n-hexane, n-heptane, n-octane, hydrogen, oxygen, carbon monoxide, water, helium, argon, n-nonane, n-decane, and hydrogen sulphide. The normal range of validity of GERG-2008 covers temperatures of $90 \mathrm{~K} \leq T \leq 450 \mathrm{~K}$ and pressures of $P \leq 35$ $\mathrm{MPa}$. The uncertainty of GERG-2008 in gas phase density and speed of sound is less than $0.1 \%$ in the temperature range from $250 \mathrm{~K} / 270 \mathrm{~K}$ to $450 \mathrm{~K}$ at pressures up to $35 \mathrm{MPa}$. In the liquid phase, the uncertainty of GERG-2008 in density amounts to less than 0.1 to $0.5 \%$ for many binary and multi-component mixtures. The estimated uncertainty in liquid phase (isobaric) enthalpy differences is less than 0.5 to $1 \%$. The vapour-liquid equilibrium is described with reasonable accuracy. Accurate vapour pressure data for binary and ternary mixtures consisting of the natural gas main components are reproduced by GERG2008 to within their experimental uncertainty, which is approximately 1 to $3 \%$.
Solving Eqns. (4)-(10) yields the pressure $(P)$, temperature $(T)$, gas density $(\rho)$, outflow speed $(u)$, speed of sound $(C)$ and friction factor $(f)$ for different times $(t)$ and different locations $(x)$. In order to calculate the decompression wave speed $(W)$, we first determine the times at which a certain pressure level reaches several given locations in the pipe and then plot the locations against the times. Linear regression of the locationtime curve yields a slope, which is the decompression wave speed.

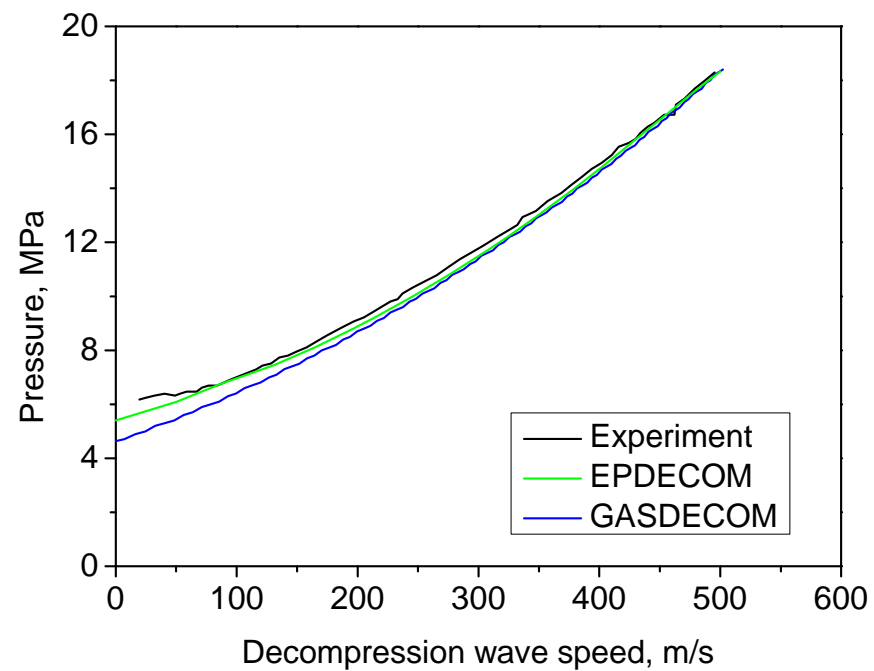

(a) Reference Test

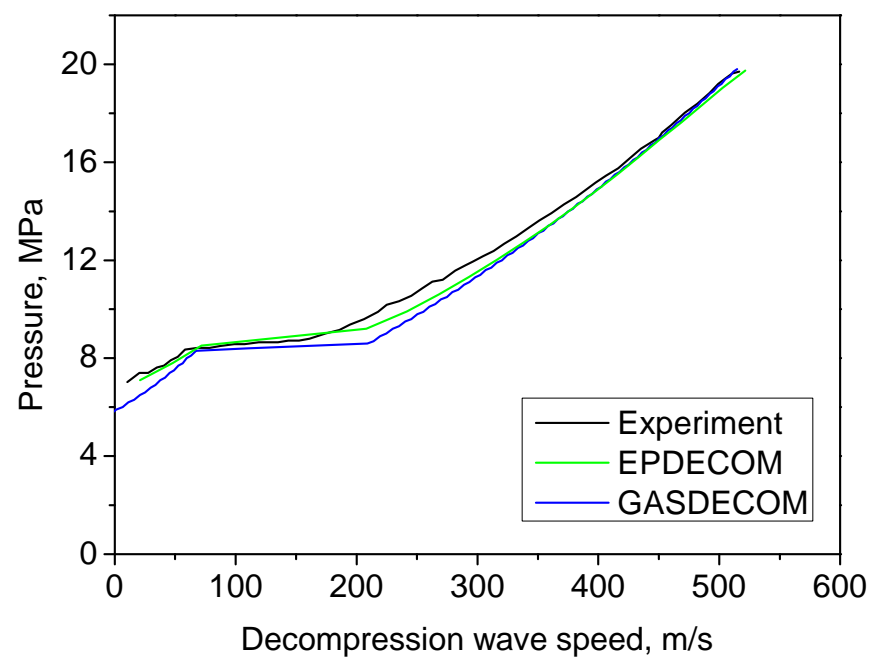

(b) Test 4

Fig. 1 Comparisons of simulation results and experimental results for Reference test and Test 4

\section{RESULTS}

Fig. 1 shows comparison of the measured and simulated decompression wave speeds for Reference Test and Test 4 . The simulation results by GASDECOM are also plotted in the figure. It can be found that both EPDECOM and GASDECOM predict accurate results at pressures near the initial pressure. As 
the pressure decreases, the prediction difference between models increases. Compared to the experimental results, the decompression wave speeds predicted by EPDECOM more closely reflect the experimental results than GASDECOM.

Fig. 1(b) shows that there are still gaps between EPDECOM simulation results and experimental results, especially for the pressures around the plateau pressure. This may be due to the inaccurate Darcy factor model. We enlarge the Darcy friction factor $(f)$ calculated by Eqn. (5) by a factor of 4 and compare the results in Fig. 2. It can be seen that EPDECOM with the enlarged friction factor gives a better prediction. This indicates that the friction factor model needs to be improved in the future research.

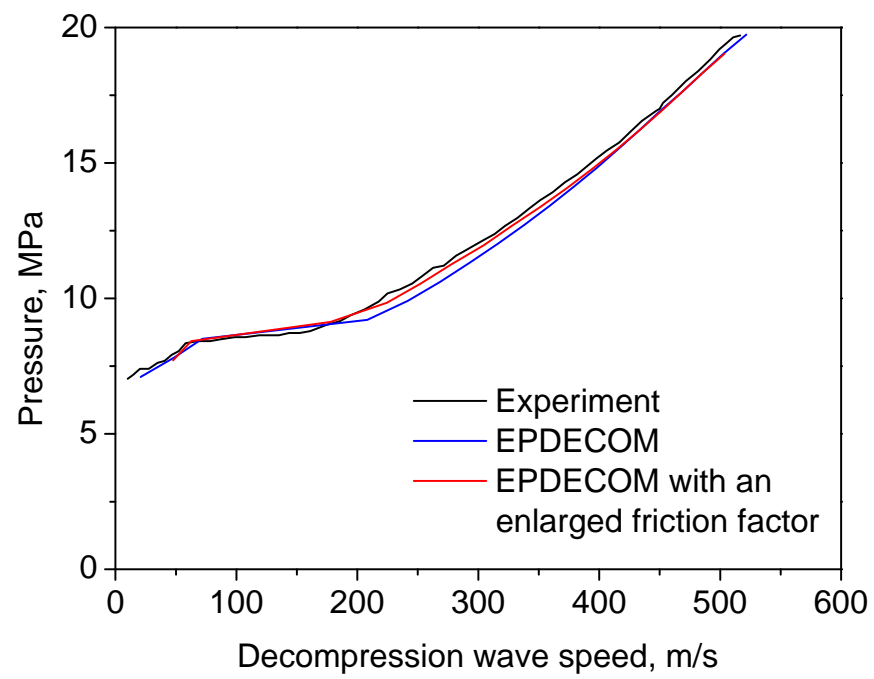

Fig. 2 Comparison of experiment, EPDECOM and EPDECOM with an enlarged friction factor for Test 4

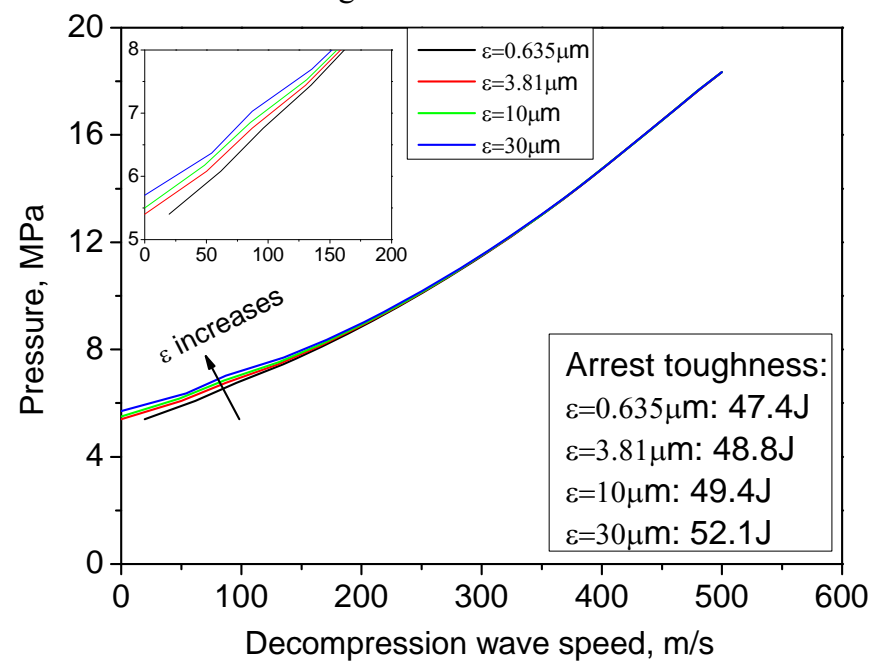

Fig. 3 Effect of roughness on decompression wave speed for $\mathrm{D}=38.1 \mathrm{~mm}$ and the same gas composition as Reference Test

Fig. 3 shows the pressure vs. decompression wave speed $(P-W)$ curves for $\mathrm{D}=38.1 \mathrm{~mm}$ and various roughnesses between $\varepsilon=0.635 \mu \mathrm{m}$ and $\varepsilon=30 \mu \mathrm{m}$. The gas composition is same as Reference Test. The insert at the left-top corner of the figure gives details for lower pressures. Similar to the experimental observation, the $P-W$ curve moves upward when the roughness increases.

If this decompression speed data was used to calculate the arrest toughness in a $457 \mathrm{~mm}$ OD, X70 pipeline with a design factor of 0.72 , the calculated toughness changes from $47.4 \mathrm{~J}$ to $52.1 \mathrm{~J}$ when roughness varies from $\varepsilon=0.635 \mu \mathrm{m}$ to $\varepsilon=30 \mu \mathrm{m}$ (see the insert in Fig. 3).

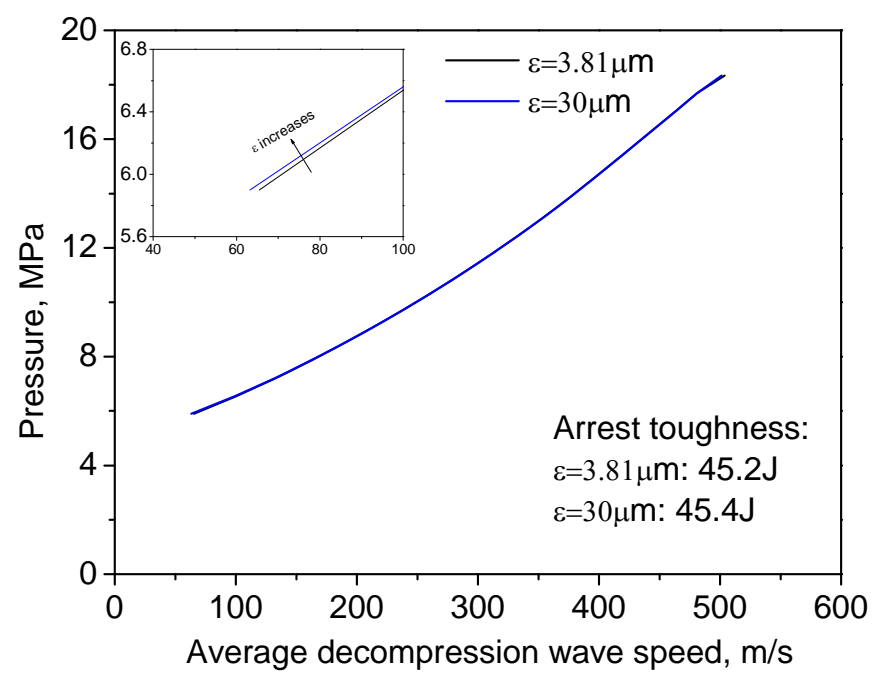

Fig. 4 Effect of roughness on decompression wave speed for $D$ $=250 \mathrm{~mm}$ and the same gas composition as Reference Test

Fig. 4 shows the effect of roughness on the decompression wave speed for $D=250 \mathrm{~mm}$. The calculation conditions in Fig. 4 are same as Fig. 3 except for the pipe diameter. Two $P-W$ curves with $\varepsilon=3.81 \mu \mathrm{m}$ and $\varepsilon=30 \mu \mathrm{m}$ are compared. Compared with results of $D=38.1 \mathrm{~mm}$ in Fig. 3, difference of $P-W$ curves in Fig. 4 is very small. To compare with the arrest toughnesses in Fig. 3, the decompression speed curve in Fig. 4 was used to calculate the arrest toughness in a $457 \mathrm{~mm}$ OD, X70 pipeline with a design factor of 0.72 . The calculated arrest toughnesses for $\varepsilon=3.81 \mu \mathrm{m}$ and $\varepsilon=30 \mu \mathrm{m}$ are $45.2 \mathrm{~J}$ and 45.4 $\mathrm{J}$, respectively, for $D=250 \mathrm{~mm}$.

The above simulation results indicate that the effect of roughness on the decompression wave speed depends on pipe diameter. For small pipe diameters $(D<250 \mathrm{~mm})$, the effect of roughness on the decompression wave speed is significant, while for $D \geq 250 \mathrm{~mm}$ this effect is negligible.

Fig. 5 shows the pressure vs. decompression wave speed $(P-W)$ curves for various roughnesses between $\varepsilon=0.635 \mu \mathrm{m}$ and $\varepsilon=30 \mu \mathrm{m}$ and other conditions same as Test 4 (Rich gas). The pipe diameter used in the simulation is $D=38.1 \mathrm{~mm}$. Fig. 6 shows the results for $D=250 \mathrm{~mm}$. The insert at the left-top corner of the figure gives details for lower pressures. 


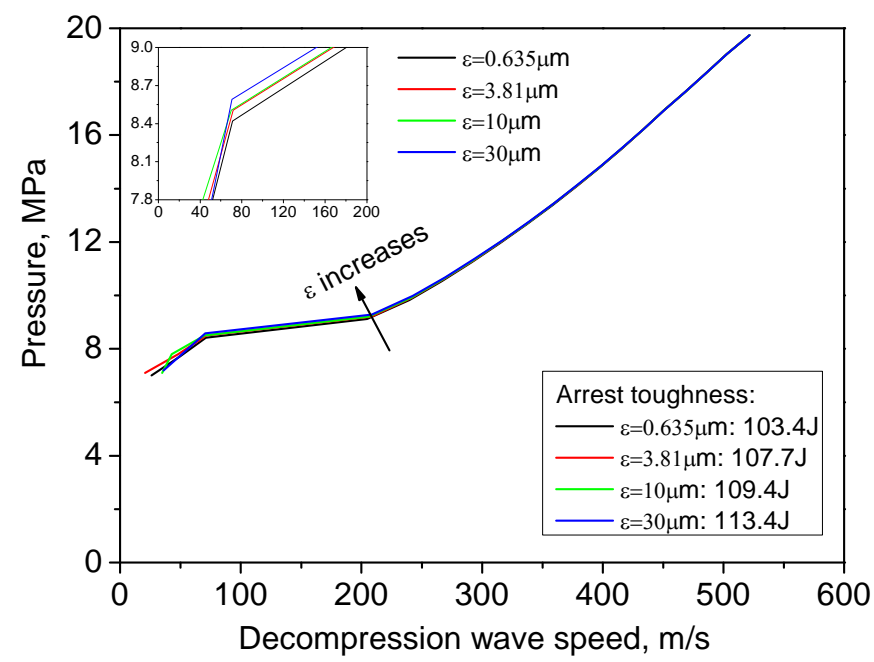

Fig. 5 Effect of roughness on decompression wave speed for $D$ $=38.1 \mathrm{~mm}$ and the same gas composition as Test 4

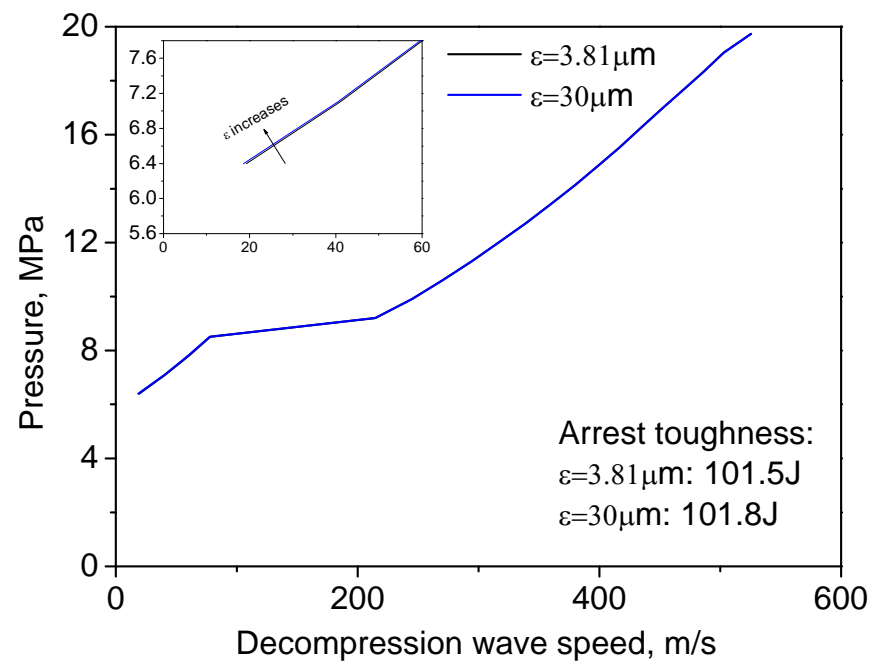

Fig. 6 Effect of roughness on decompression wave speed for $D$ $=250 \mathrm{~mm}$ and the same gas composition as Test 4

Similar to the experimental observation, the $P-W$ curve moves upward when the roughness increases. If the decompression speed curves in Figs. 5 and 6 were used to calculate the arrest toughness in a $457 \mathrm{~mm}$ OD, X70 pipeline with a design factor of 0.72 , the corresponding arrest toughnesse were determined and displayed in the figures. For $D$ $=38.1 \mathrm{~mm}$, arrest toughness is increased by $5.29 \%$ from 107.7

$\mathrm{J}$ to $113.4 \mathrm{~J}$ when roughness is increased from $\varepsilon=3.81 \mu \mathrm{m}$ to $\varepsilon$ $=30 \mu \mathrm{m}$ while the increase of the arrest toughness for the same roughness change is reduced to $0.3 \%$ for $D=250 \mathrm{~mm}$.

The simulation results of the rich gas confirm the finding of the lean gas, namely the effect of roughness on the decompression wave speed depends on pipe diameter.

Fig. 7 shows the effect of pipe diameter $(D)$ on the decompression wave speed with other conditions same as
Reference Test (Lean gas). The insert gives the details of the $P$ $W$ curves for lower pressures.

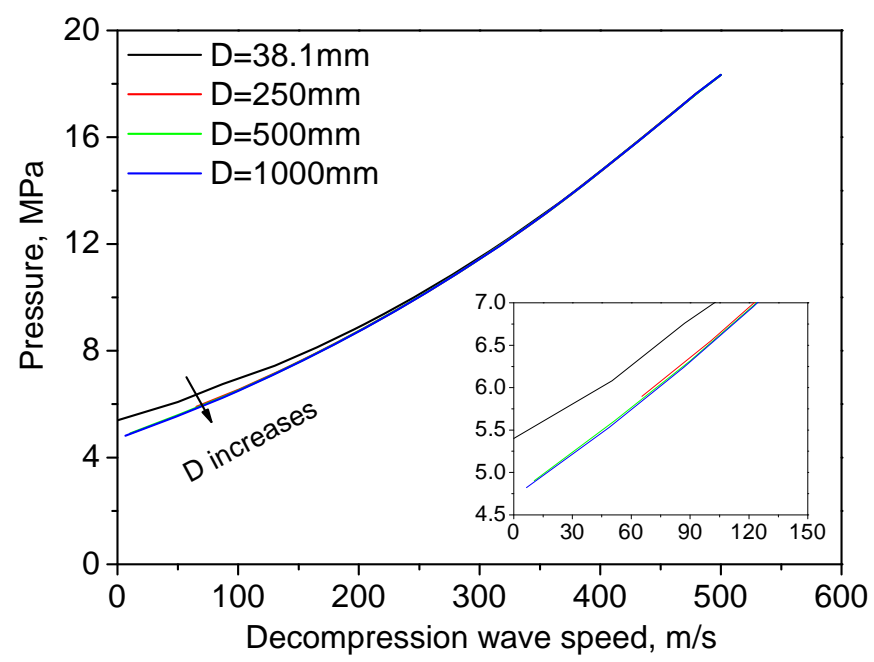

Fig. 7 Effect of pipe diameter on decompression wave speed for $\varepsilon=3.81 \mu \mathrm{m}$ and the same gas composition as Reference Test

When $D$ increases from $38.1 \mathrm{~mm}$ to $250 \mathrm{~mm}$, the $P-W$ curve significantly decreases at the low pressure region. However, as $D$ further increases to $500 \mathrm{~mm}$, the change of the $P-W$ curve becomes very small. It is hardly to see the difference in the $P-W$ curves between $D=500 \mathrm{~mm}$ and $D=1000 \mathrm{~mm}$.

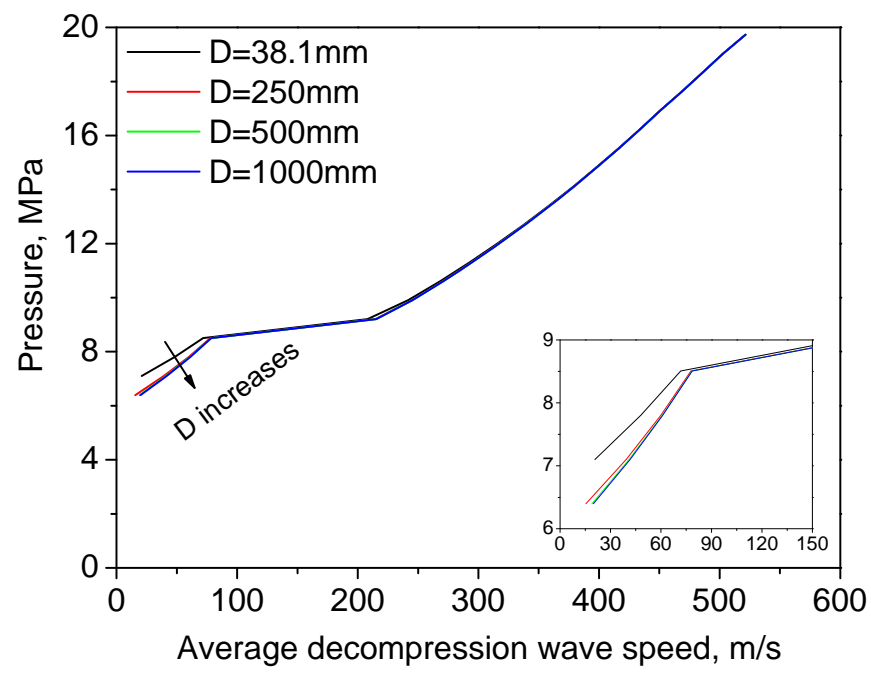

Fig. 8 Effect of pipe diameter on decompression wave speed for $\varepsilon=3.81 \mu \mathrm{m}$ and the same gas composition as Test 4

Fig. 8 shows the effect of pipe diameter on the decompression wave speed for the case of Test 4 (Rich gas). Though the gas composition and initial pressure in Fig. 8 are different to those in Fig. 7, the same phenomenon is observed, namely pipe diameter only plays an important role for $D<250$ mm pipes. 
Above analysis indicates that pipe diameter affects significantly the decompression wave speed and arrest toughness for small diameter pipes (roughly $D<250 \mathrm{~mm}$ ), while its effect is insignificant for pipes with $D \geq 250 \mathrm{~mm}$.

\section{DISCUSSION}

The local decompression wave speed is calculated by Eqn. (11), namely

$$
W=-\frac{\partial P / \partial t}{\partial P / \partial x}=C-u-\frac{\rho C f}{2 D(\partial P / \partial x)} u^{2}
$$

The third term in Eqn. (11) $\left(-\frac{\rho C f}{2 D(\partial P / \partial x)} u^{2}\right)$ represents the effects of roughness and pipe diameter on the decompression wave speed. Eqn. (11) shows that $W$ is a function of $f$ and $D$. In addition, the change in roughness or pipe diameter also influences the pressure $(P)$, density $(\rho)$, outflow speed $(u)$ and speed of sound $(C)$, and in turn affects indirectly the decompression wave speed $(W)$. Eqn. (11) can be rewritten as:

$$
\begin{aligned}
& W=C-u-\alpha K u^{2} \\
& \alpha=\frac{f}{D} \\
& K=\frac{\rho C}{2(\partial P / \partial x)}
\end{aligned}
$$

$\alpha$ represents the direct effect of roughness and pipe diameter on the decompression wave speed, while $K$ represents the indirect effect. $\alpha$ is a nondimensional factor. The detailed EPDECOM calculation indicates that the direct effect $(\alpha)$ is dominant. Therefore, we assume $K$ is independent of roughness and pipe diameter in the following analysis. Eqns. (5), (6) and (14) show that the direct effect factor $(\alpha)$ is related to the ratio of roughness to pipe diameter $(f=\varepsilon / D)$ and pipe diameter $(D)$.

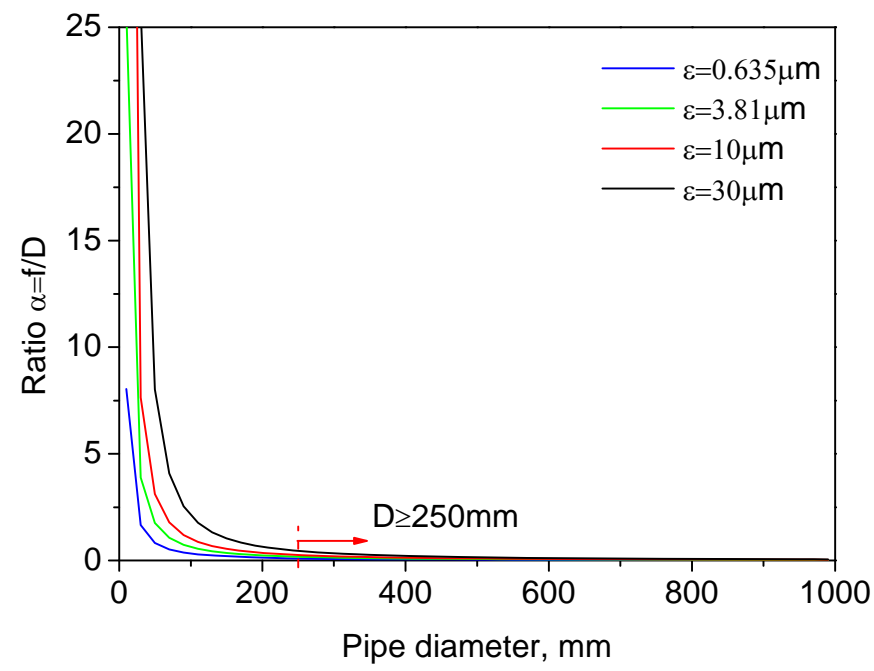

Fig. 9 Direct influence factor as a function of pipe diameter for four different roughnesses
In Fig. 9, $\alpha$ is shown as a function of $D$ for four different roughness values under a condition of $R e=1 \times 10^{8}$. $\alpha$ has a large value for very small pipe diameter and it decreases rapidly when pipe diameter increases for $D<100 \mathrm{~mm}$ indicating that pipe diameter affects significantly the decompression wave speed for small diameter pipes. As $D$ increases, the magnitudes of the slopes of the curves decrease. This means that the effect of pipe diameter on the decompression wave speed is reduced with pipe diameter. When the pipe diameter is greater than 250 $\mathrm{mm}, \alpha$ has become a very small values for all four roughness cases as shown in Fig. 9. This is reason why the effect of pipe diameter is small for pipes with $D \geq 250 \mathrm{~mm}$ in the EPDECOM simulation results.

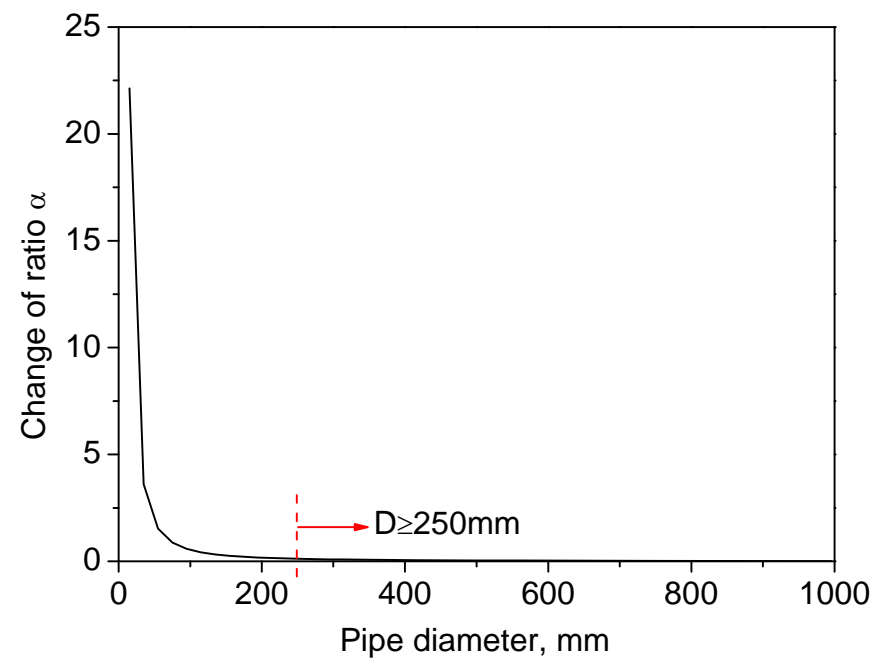

Fig. 10 Change of ratio $\alpha$ caused by roughness change from 0 $\mu \mathrm{m}$ to $10 \mu \mathrm{m}$ as a function of pipe diameter

If the roughness changes from $\varepsilon=0 \mu \mathrm{m}$ to $10 \mu \mathrm{m}$, the change of ratio $\alpha(\Delta \alpha)$ can be calculated by $\Delta \alpha=\alpha(\varepsilon=10 \mu \mathrm{m})$ $\alpha(\varepsilon=0 \mu \mathrm{m})$. Since $K$ has been assumed to be constant, $\Delta \alpha$ represents of the effect of the change in roughness for a pipe diameter.

Fig. 10 shows $\Delta \alpha$ as a function of pipe diameter. $\Delta \alpha$ has a large value for small diameter, indicating that roughness has a significant effect on the decompression wave speed for small diameter pipes. $\Delta \alpha$ decreases rapidly with pipe diameter and approaches nearly zero after $D$ is greater $250 \mathrm{~mm}$. This is consistent with the simulation results which show that the effect of roughness is insignificant for $D \geq 250 \mathrm{~mm}$ pipes.

\section{CONCLUSIONS}

The conclusions of the report include:

(a) A one-dimensional dynamic simulation model, named EPDECOM, was developed to investigate the effects of wall roughness and pipe diameter. Compared to the shock tube experimental results, EPDECOM predicts better results than the commonly used model GASDECOM. 
(b) EPDECOM simulation results show that the increased pipe wall roughness reduces the decompression wave speed and enhances arrest toughness. The effect of roughness is significant for small diameter pipes (roughly $D<250 \mathrm{~mm}$ ), while this effect is negligible for pipes with $D \geq 250 \mathrm{~mm}$. This shows that the evaluation of the potential effect on arrest toughness in DN450 diameter pipe presented from the shock tube test results is conservative.

(c) EPDECOM simulation results show that the decompression wave speed is nearly independent on pipe diameter for pipes with $D \geq 250 \mathrm{~mm}$.

\section{ACKNOWLEDGMENTS}

This work was funded by the Energy Pipelines CRC, supported through the Australian Government's Cooperative Research Centres Program. The cash and in-kind support from the APIA RSC is gratefully acknowledged. Authors also appreciate PRCI, TransCanada Pipeline and Alliance Pipeline for their supports to the shock tube experiments.

\section{REFERENCES}

[1] A. B. Rothwell, Fracture Propagation Control for Gas Pipelines - Past, Present and Future, Pipeline Technology, Vol. 1, 2000, 387-405

[2] W. A. Maxey, Fracture Initiation, Propagation and Arrest. 5th Symposium on Line Pipe Research, p. J-1. PRCI Catalogue No. L30174. 1974,

[3] R. J. Eiber, T. A. Bubenik and W. A. Maxey, Fracture Control for Natural Gas Pipelines. PRCI Catalogue No. L51691, 1993.

[4] S. Igi, S. Kawaguchi and N. Suzuki, Running Ductile Fracture Analysis for X80 Pipeline in JGA Burst Tests, Pipeline Technology Conference, Ostend, 12-14 October 2009, Paper no: Ostend2009-068

[5] R. M. Andrews and N. A. Millwood, The Fracture Arrest Behaviour Of 914 Mm Diameter X100 Grade Steel Pipelines, Proceedings of IPC 2004 International Pipeline Conference October 4 - 8, 2004 Calgary, Alberta, Canada, IPC04-0596

[6] H. Makino, I. Takeuchi and R. Higuchi, Fracture Propagation And Arrest In High-Pressure Gas Transmission Pipeline By Ultra High Strength Line Pipes, Proceedings of IPC2008, 7th International Pipeline Conference September 29October 3, 2008, Calgary, Alberta, Canada, IPC2008-64078

[7] S. Kawaguchi, K. Murai, Y. Hashimoto et al., Full-Scale Burst Tests Of Ultra-High Pressured Rich-Gas Pipelines Under Buried And Unburied Conditions, Proceedings of IPC2008, 7th International Pipeline Conference September 29-October 3, 2008, Calgary, Alberta, Canada, IPC2008-64434

[8] H. Makino, I. Takeuchi, and R. Higuchi, Fracture arrestability of high pressure gas transmission pipelines by high strength linepipes, Pipeline Technology Conference, Ostend, 12-14 October 2009, Paper no: Ostend2009-008

[9] K. K. Botros, J. Geerligs, B. Rothwell et al., Effects of Pipe Internal Surface Roughness on Decompression Wave Speed in
Natural Gas Mixtures, Proceedings of IPC 2010 8th International Pipeline Conference September 27-October 1, 2010, Calgary, Alberta, Canada, IPC2010-31667

[10] K.K. Botros, J. Geerligs, J. Zhou and A. Glover, Measurements of flow parameters and decompression wave speed following rupture of rich gas pipelines, and comparison with GASDECOM, International Journal of Pressure Vessels and Piping 84 (2007) 358-367

[11] A. G. Phillips and C. G. Robinson, Gas Decompression Behavior following the Rupture of High Pressure Pipelines Phase 2: Modeling Report, PRCI Contract PR-273-0135, November 2005.

[12] A. G. Phillips and C. G. Robinson, Gas Decompression Behavior following the Rupture of High Pressure Pipelines Phase 1, PRCI Contract PR-273-0135, November 2002.

[13] D. M. Johnson, P. S. Cumber, N. Horner, L. Carlson and R. Eiber, Full-Scale Fracture Propagation Experiments: A Recent Application and Future Use for the Pipeline Industry, Proceedings of the ASME International Pipeline Conference, Calgary, 1-5 October 2000

[14] T. K. Groves, P. R.Bishnoi and J. M. E. Wallbridge, Decompression Wave Velocities in Natural Gases in Pipe Lines, The Canadian Journal of Chemical Engineering,Vol. 56, pp 664 - 668, December 1978.

[15] D. G. Jones and D. W. Gough, Rich Gas Decompression Behaviour in Pipelines, AGA-EPRG Linepipe Research Seminar IV, Duisburg, 22 - 24 September 1981

[16] H. Makino, T. Sugie, H. Watanabe, T. Kubo, T. Shiwaku, S. Endo, T. Inoue, Y. Kawaguchi, Y. Matsumoto and S. Machida, Natural Gas Decompression Behavior in High Pressure Pipelines, ISIJ International, Vol. 41, pp 389 - 395, 2001

[17] K. K. Botros, Performance of Five Equations of State for the Prediction of VLE and Densities of Natural Gas Mixtures in the Dense Phase Region, Chem. Eng. Comm., 2002, Vol. 189(2), 151

[18] W. Wagner, Description of the Software Package for the Calculation of Thermodynamic Properties from the GERG2004 XT08 Wide-Range Equation of State for Natural Gases and Other Mixtures, April 2009 
